\title{
Model of Thailand Speech Intelligibility (T-SI) in the Large Classrooms from Public University
}

\author{
Pasit Leeniva ${ }^{1} \&$ Prapatpong Upala ${ }^{1}$ \\ ${ }^{1}$ Faculty of Architecture, King Mongkut's Institute of Technology Ladkrabang (KMITL), Bangkok, Thailand \\ Correspondence: Pasit Leeniva. Multidisciplinary Design Research, Faculty of Architecture, King Mongkut's \\ Institute of Technology Ladkrabang, Bangkok, Thailand. Tel: 6686-3699-266. E-mail: pasitlee@gmail.com
}

Received: April 8, 2017

doi:10.5539/ass.v13n7p69
Accepted: May 24, $2017 \quad$ Online Published: June 23, 2017

URL: https://doi.org/10.5539/ass.v13n7p69

\begin{abstract}
The objectives of this research are to evaluate acoustic environments and to forecast STI values from spatial component variables in the large classrooms of the Thai public university that were specially controlled the same room finishing materials including the floor, walls, and ceiling. Whereas the five spatial component factors included (1) Room Volume (RV), (2) Ceiling Height (CH), (3) the Ratio of Depth to Width $\left(\mathrm{R}_{\mathrm{dw}}\right)$, (4) Total Room Surface (TS), and (5) Percentage of Absorbing Surface areas (PAS). The research tools were the smartphones that used the applications for acoustical evaluation and speech intelligibility analysis. The Speech Transmission Index (STI), Reverberation Time (RT), and Background Noise Level (BNL) were collected by the calibrated microphone in the nine points distributed across the entire room. And also, the sounds for testing were simulated such as balloon burst, and STIPA signal via a sound generator. The Thailand Speech Intelligibility (T-SI) model was developed by the multiple regression analysis with a statistical at a confidence level of $95 \%$.The results showed that this T-SI model depended on the strongly positive relationship of PAS and the slightly positive relationship of $\mathrm{CH}$, TS while the $\mathrm{RV}, \mathrm{R}_{\mathrm{dw}}$ were slightly the negative relationship and which predicted STI values. Moreover, the highest affecting variable of T-SI model was CH and the lowest was PAS. However, this research implies that the improving room acoustic quality would be adjusting the sound absorbing surface areas i.e., increase the cloth curtain or appropriate methods.
\end{abstract}

Keywords: acoustical measurement, classroom acoustic, spatial component, speech intelligibility

\section{Introduction}

\subsection{Research Background and Conceptual Framework}

The acoustical conditions in classrooms were the important issues to realize. It is well known that the poor acoustical problems have substantial effects on the learning process. In order to achieve the good indoor acoustical environment, the spatial aspect needs more attention and study in depth (Barron, 2001). The acoustical environment is generated from the responses of spatial component factors in the interior environment (Paradis, 2014) that comprise room volume, ceiling height, the ratio of depth to width, total room surface, and absorption surface areas. These factors affect acoustical characteristics that occur (Zannin \& Marcon, 2007; Rabelo et al., 2014). Therefore, this research was conducted under the conceptual framework shown in Figure 1.

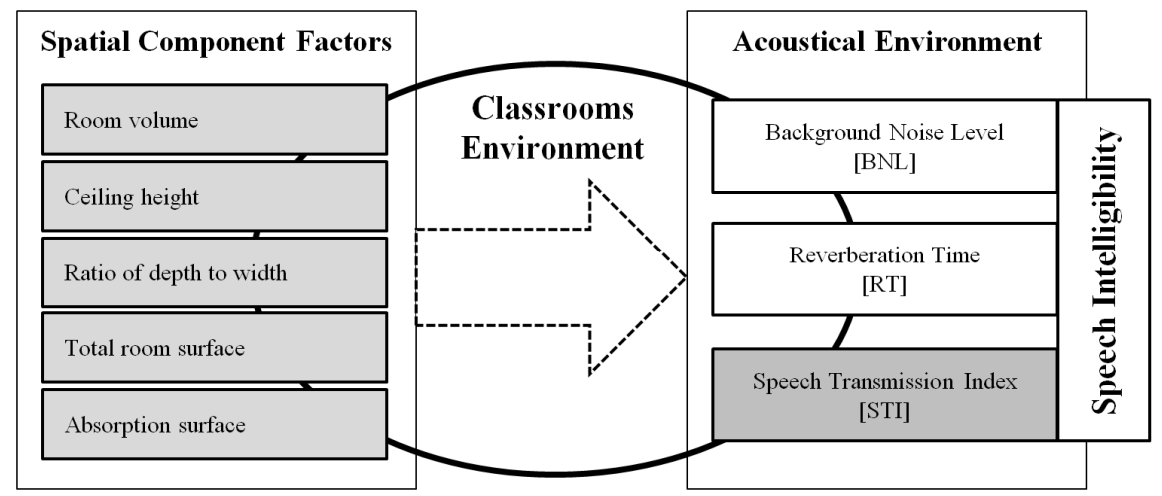

Figure 1. Research conceptual framework 
The figure displays connections of two aspects of the acoustical environment and the physical environment, where furniture and construction material variables are not considered. The objectives of this research are (1) to evaluate classrooms acoustical environment and (2) to forecast speech transmission index: STI values, which is affected by spatial component variables. This paper comprises four sections of content included (1) Introduction which explains the origin of this research as well as literature reviews relating to spatial components of large classrooms and speech transmission index. (2) Data collection steps and equipment installation guidelines for room acoustical measurements. (3) Research results which are separated into three sections, namely, spatial component data summarization, descriptive statistic values such as BNL, RT, and STI of each room comparing with their standard values. The last result section is the statistical analysis which is summarized into regression equation between STI value and five spatial component factor aspects. And (4) research conclusion.

\subsection{Previous Studies of Classroom Acoustics}

There are many studies have investigated the acoustical environment in classrooms. Due to classrooms are areas where clear speech communication must be concerned. In order to build understanding between instructors and students, the speech lecturing is an indispensable requirement (Sala \& Viljanen, 1995; Nijs \& Rychtarikova, 2011). Previous studies posited that poor acoustic classrooms, reverberant classrooms, and unclear communication will affect reading and learning quality. Moreover, it can negatively affect attitude and emotion towards the learning environment (Klatte \& Hellbruck, 2010; Asutay et al., 2012). The clear speech communication in classrooms should be evaluated by acoustical parameters such as Speech Transmission Index (STI), Reverberation Time (RT) and Background Noise Level (BNL) (Bradley, 1986a; Bradley, 1986b; Hodgson, 1999; Bistafa \& Bradley, 2000).

However, studies about the acoustic clarity of classrooms in Thailand are scarce and insufficient. Additionally, interior designers and architects might not realize the importance of acoustic environment in classrooms. This can be seen from classrooms design in Thailand which the finishing materials are constructed with smooth shiny materials to serve only cleaning and maintenance purposes. Also, sound absorbing materials are not installed in classrooms and such environments can cause noisy and reverberant conditions (Fuchs et al., 2001; Larm et al., 2005), aligned with Sabine formula, which indicates reverberation time that is the result of room volume factors and room acoustic absorption (Astolfi, Corrado, \& Griginis, 2008). Therefore, the spatial component factors are the variables that affect the acoustical environment in classrooms.

\subsection{Speech Transmission Index (STI), Background Noise Level (BNL), and Reverberation Time (RT)}

Speech Transmission Index (STI) is one of the parameters that used to measure verbal communication clarity (Tang \& Yeung, 2003). Figure 2 shows the meaning of STI value at each level starting from 0 to 1 , where 0 refers to unclear and 1 refers to very clear (Sala \& Viljanen, 1995). STI, therefore, is important to rooms or verbal communication areas (Leeniva \& Upala, 2015) especially classroom areas which need to have an STI value higher than 0.6 (Rabelo et al., 2014). STI value is directly related to Background Noise Level (BNL) and Reverberation Time (RT), and also related to the physical environment in rooms (Peng, 2010; Leeniva \& Upala, 2017).

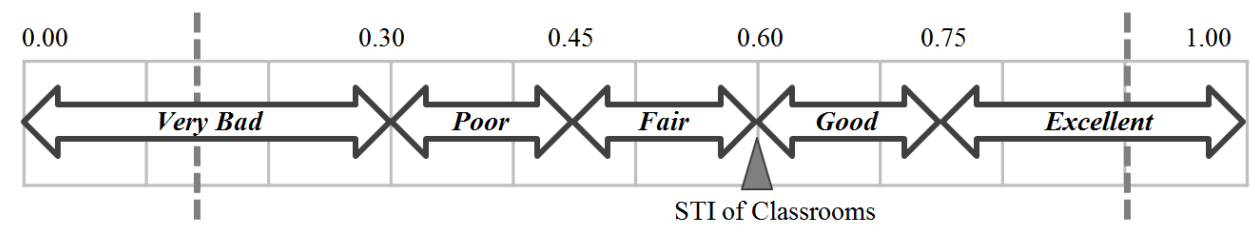

Figure 2. Verbal-communication clarity reference chart base on value level and its meaning for STI

Background Noise Level (BNL) or ambient noise is a value that measures sound loudness while no educational activities are being conducted in the classroom. The sound level unit that is used as an international standard is A-weighted decibels (dBA). And Reverberation Time (RT) refers to echo duration, using seconds as its measuring unit, also called RT or RT60. RT60 refers to the measurement method that produces sound with 60 $\mathrm{dBA}$ louder than BNL level; the time until the sound disappears and returns to normal BNL level is recorded (Fuchs et al., 2001). American National Standards Institute (ANSI) showed that reverberant condition and high noise level within a room are the cause of unclear communications, especially in large volume rooms which have a higher chance of occurring than small volume rooms (ANSI, 2002). ANSI S12.60 specifies the standard values 
of BNL under no activity conditions to be $35-40 \mathrm{dBA}$, and standard RT value to be 0.7 seconds for large classrooms, display in Table 1. If BNL and RT index values exceed that of their standard, it will cause the reduction in STI value and negatively affect verbal communication clarity (ANSI S12.60, 2002; Astolfi et al., 2008; Sala \& Viljanen, 1995; Tang \& Wong, 1998).

Table 1. The standardized value of acoustical indexes for large classrooms

\begin{tabular}{lccc}
\hline Acoustical indexes & Value & Standards & Years of definition \\
\hline Background Noise Level (BNL) & $35-40 \mathrm{dBA}$ & ANSI S12.60 & 2002 \\
Reverberation Time (RT) & $\leq 0.7$ second & ANSI S12.60 & 2002 \\
Speech Transmission Index (STI) & $\geq 0.60$ & IEC 60268-16 ed.4.0 & 2011 \\
\hline
\end{tabular}

\section{Method}

\subsection{Research Procedure}

This research plan is separated into three main steps containing the following details:

Step 1: Physical room assessment was conducted by measuring six classroom areas then summarizing spatial component factors, namely room volume, ceiling height, the ratio of depth to width, total room surface and percentage of absorption surface.

Step 2: Acoustical Measurement of the three acoustical indexes, namely, BNL, RT, and STI. Those indexes were collected under sound simulation control in classrooms. The sound level was kept constant by a sound generator, and acoustical values were measured via smartphone application connected to the calibrated measurement microphones. Measurement of RT value used the impulse noise (balloon burst sound with sound level $=\mathrm{BNL}+60 \mathrm{dBA}$ ) and the STIPA signal was used to measure STI value.

Step 3: The research results are separated into two sections, namely, Section 1: Comparing descriptive statistics, showing three acoustical indexes, which are BNL, RT, and STI, between the six large classrooms, as well as comparison of the obtained values with ANSI S12.60 (2002) and IEC 60268-16 standard (2011). Also, results were shown in the way of contour maps using Surfer V13 to display sound distribution characteristics within the rooms. Section 2: Result analysis via regression statistics was used to formulate the model of Thailand Speech Intelligibility (T-SI)

\subsection{The Study Area: Large classrooms in Public University}

The classrooms under study are located in a Thai public university that conducts bachelor level courses. King Mongkut's Institute of Technology Ladkrabang (KMITL) was specifically chosen due to the institute's location nearby Suwannabhumi International Airport within a $10 \mathrm{~km}$ radius. Also, this institute has studied the impacts from the airport after it started operating in 2006 by Pollution Control Department of Thailand. The study found that this institute receives the impact of noise during airplane takeoff-landing at an average of $60-65 \mathrm{dBA}$. Apart from this, it also receives noise pollution from other communication systems such as railways and highways (Leeniva \& Upala, 2015).

The study areas were carried out in six large classrooms. The large classrooms refer to rooms that have a volume of 288 to 566 cubic meters (ANSI S12.60, 2002) or an estimated capacity of 100 to 120 seats. In this study, six rooms were selected as representatives of six faculties that conduct bachelor level courses (Figure 3). Each room contains the same finishing materials, namely, polished stones or smooth floor tiles as floor material, smooth gypsum board as ceiling material, concrete plaster brick or smooth surface gypsum board as wall materials, as shown in Figure 4. The differences of each room depend on spatial component factors, which cause variation in the acoustical environment (Paradis, 2014). The factors consist of room volume, ceiling height, the ratio of depth to width, total room surface, and absorption surfaces (Rabelo et al., 2014). During data collection, all furniture was removed and no educational activities were conducted (Peng, 2010). 


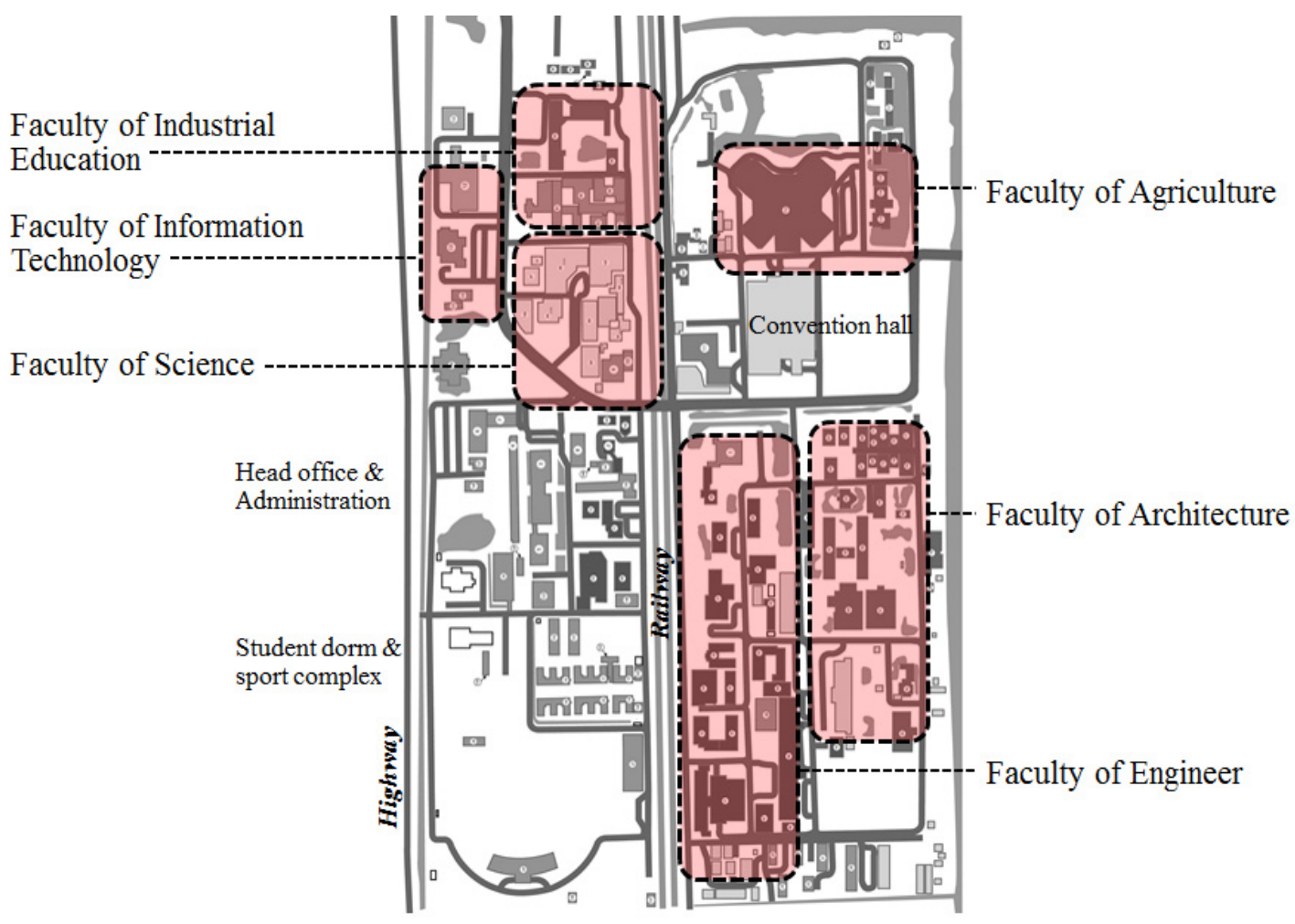

Figure 3. Six faculties in KMITL
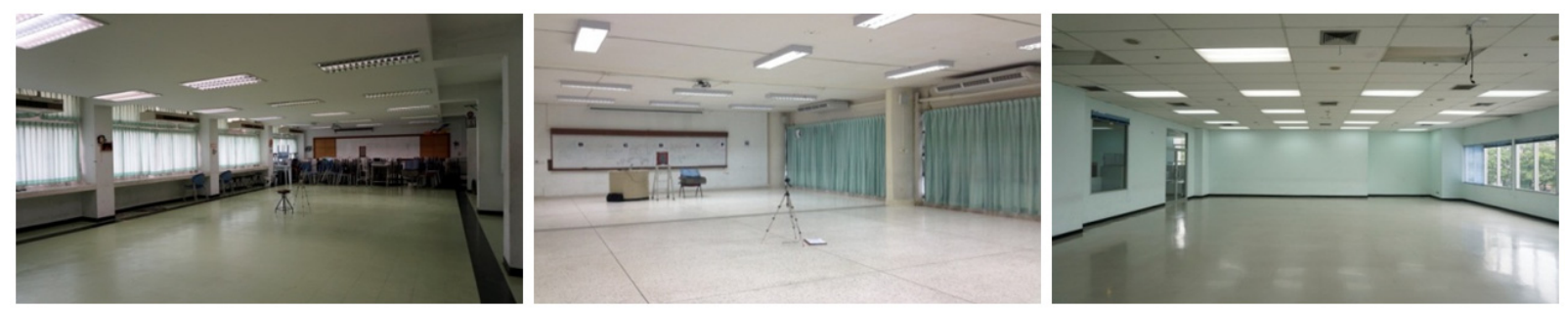

Figure 4. Display floor, walls, and ceiling materials of the large classrooms in KMITL

In the data collecting procedures, purposive sampling was utilized. Each classroom in this study represents classrooms provided for undergraduate students of each faculty in KMITL. Six classrooms in total were drawn from six faculties, namely Faculty of Engineer, Faculty of Industrial Education, Faculty of Architecture, Faculty of Science, Faculty of Agriculture and Faculty of Information Technology. All sampled classrooms had the following criteria; 1) They must be large classrooms with room volume between 288-566 cubic meters; 2) They must be air-conditioned with closed windows and doors; 3) They must be rectangular or shoe box shape; 4) They must be rooms for lecturing or seminar only (laboratories or multi-function rooms were excluded).

\subsection{Room Acoustical Measurements}

Room acoustical measurements were collected three acoustical indexes, namely, The Speech Transmission Index (STI), Reverberation Time (RT), and Background Noise Level (BNL), by smartphone applications iSTI, APM tool, and SPL respectively. These evaluations were conducted through Dayton Calibrated Measurement Microphone, iMM-6 model. Both applications and microphones were certified by the International Electrotechnical Commission (IEC). Table 2 shows equipment details, the application used in an acoustic analysis, and certified standards. Data collection equipment used is shown in Figure 5 and consisted of a microphone for measurement, the adjustable microphone stand, iphone5s with IOS 9.3, record forms, computer, and speaker. 
Table 2. Acoustic measuring equipment and acoustic analyzing applications

\begin{tabular}{lll}
\hline Instruments and Software & Specification and Details & Standard or Certified \\
\hline Sound generator $/$ Speaker & $\begin{array}{l}\text { Roland; 6.5” neodymium speakers *2, 40-140 dBA, wide } \\
\text { dynamic range and flat. }\end{array}$ & European Directive 89 336/EEC \\
\hline Microphone $/$ Receiver & $\begin{array}{l}\text { Dayton; iMM-6 iDevice Calibrated Measurement } \\
\text { Microphone, for use with iOS, the true omnidirectional } \\
\text { pattern with calibrated flat frequency response. }\end{array}$ & IEC 60268-4 \\
\hline Sound level analyzer for BNL & SLA v2.2 by Toon.LLC, iOS application & IEC 61672-1 (2013) \& JIS C 1509-1 \\
\hline RT measurement & APM Tool v2.0 by Suonoevita, iOS application & IEC 61672 (2013) \& ISO 3382 \\
\hline STI measurement & iSTI by Embedded acoustics, iOS application & IEC 60268-16 (1998) \\
\hline
\end{tabular}
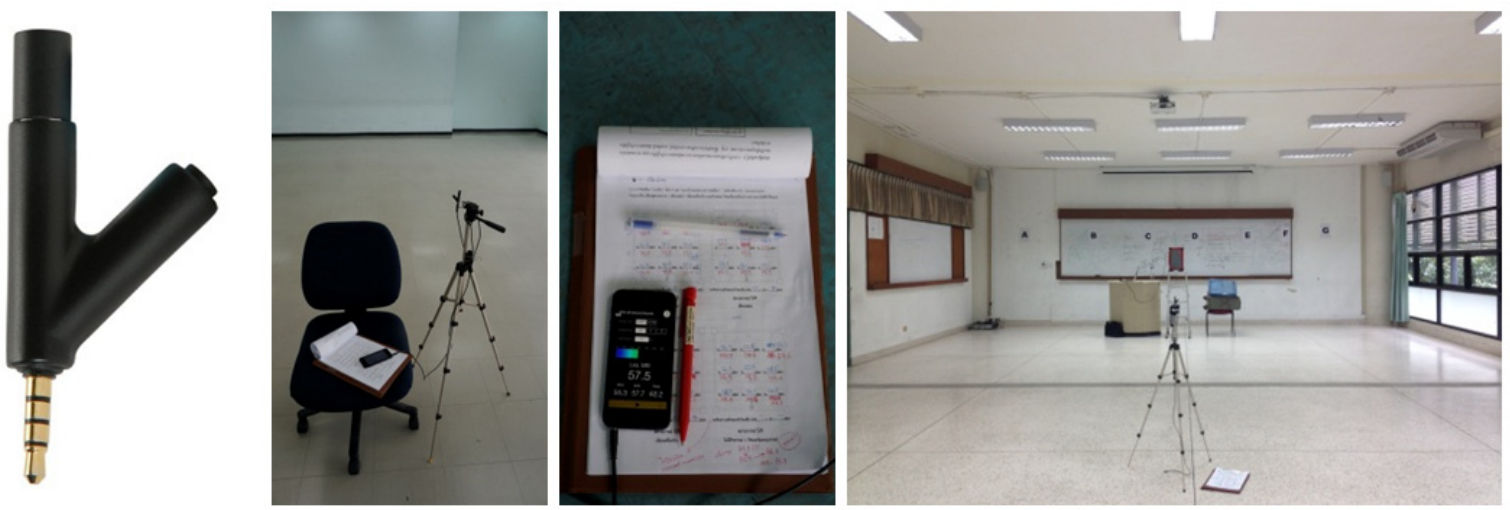

Figure 5. Equipment and tools used for room acoustical measurement

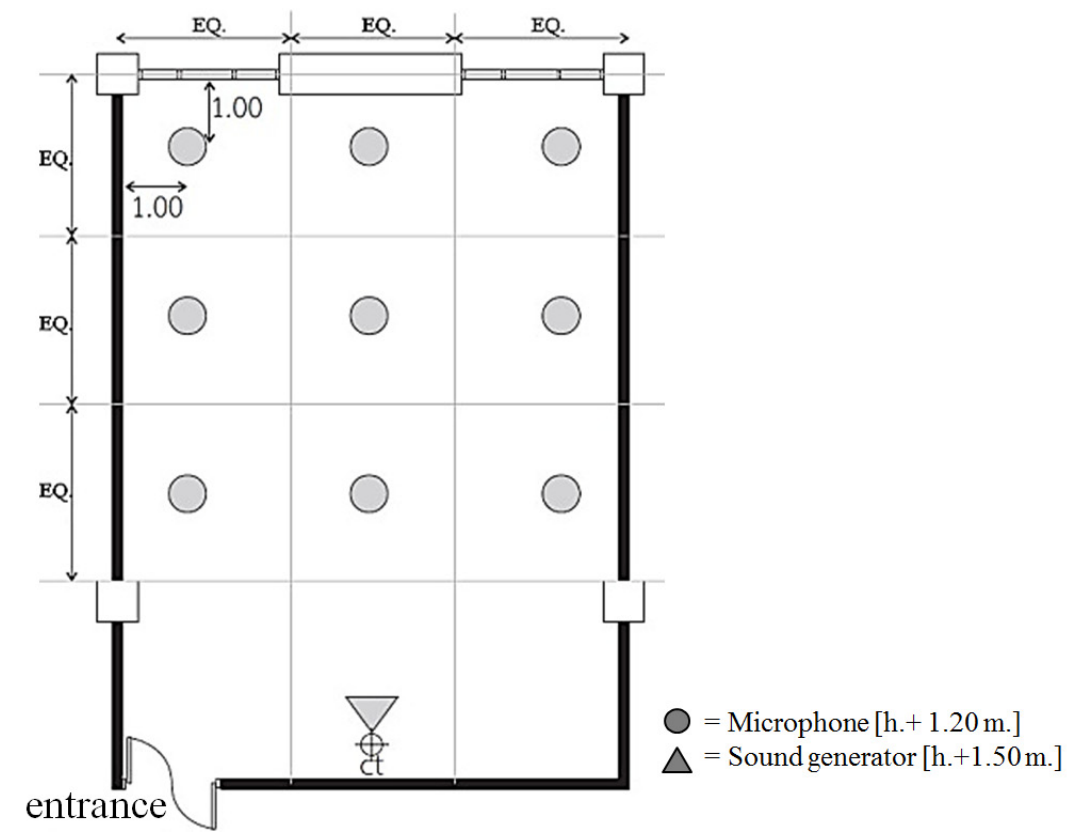

Figure 6. Equipment installation guideline for acoustical measurement room

Figure 6 shows equipment installation guideline for room acoustical measurement. The setting of a sound generator was located in a position where a lecturer stands during lecture, which is the middle-front area of the room at the height of 1.50 meters. The speaker generated two types of sound simulation such as balloon burst sound (impulse noise) and STIPA signal. For positions of the receiver, heights referred to ear level of seated 
students while listening to a lecture, which was determined to be 1.20 meters high. The positions of the receivers were specified in nine points spreading over the entire room. The positions adjacent to walls were specified to leave 1.00-meter gaps, as shown in Figure 6. In addition, BNL measurement was evaluated under a total of three situations, namely, (1) when all air-conditioning systems were turned off, (2) air-conditioning systems were turned on but no acoustic absorbing material in the room and (3) air-conditioning systems were turned on with the acoustic absorbing material in the room. Data collection was carried out at noon, on a day with no educational activities, no university students inside each building, including no activities taking place in adjacent space. The weather condition during data collection was normal; no rain, thunder, or strong wind.

\section{Results and Discussion}

\subsection{Physical Environment Analysis of Six Large Classrooms}

The overall spatial component factor data of the six studied classroom areas from six faculties in KMITL were displayed in Table 3. Every classroom was considered as a large classroom with volumes in a range of 288 to 566 cubic meters complying with ANSI S12.60 (2002) specifications. Floor, walls, and ceiling material of each room had no differences and were similar to other public institution classrooms. They consisted of smooth shiny materials that are often used due to ease of maintenance such as the polished stone floor, smooth floor tiles, and smooth padded gypsum ceiling, and most of the wall materials were smooth padded concrete and smooth padded gypsum. Therefore, there was very little to no acoustic absorbing materials in the rooms, which mostly came from blind materials on windows. The items mentioned in the table below are a summary of the studied areas, which include Room Volume (RV), Ceiling Height $(\mathrm{CH})$, the Ratio of Depth to Width $\left(\mathrm{R}_{\mathrm{dw}}\right)$, Total Room Surface (TS) and Absorbing Surface areas calculated in percentage (PAS).

Table 3. The spatial component data of the six large classrooms

\begin{tabular}{l|cccccc|ccc}
\hline & \multicolumn{7}{|c|}{ Large classrooms } & \multicolumn{2}{c}{} \\
\cline { 2 - 9 } & ENG & IDED & ARCH & SCI & AGRI & IT & Mean & S.D. & Min.-Max. \\
\hline Room Volume (RV): $\left(\mathrm{m}^{3}\right)$ & 340.00 & 403.75 & 428.34 & 318.66 & 319.73 & 422.80 & 391.74 & 46.61 & $318.66-428.80$ \\
\hline Floor Area: $\left(\mathrm{m}^{2}\right)$ & 106.25 & 161.50 & 129.80 & 120.25 & 110.25 & 140.94 & 126.06 & 14.68 & $106.25-161.50$ \\
\hline Ceiling Height $(\mathrm{CH}):(\mathrm{m})$ & 3.20 & 2.50 & 3.30 & 2.65 & 2.90 & 3.00 & 3.05 & 0.29 & $2.50-3.30$ \\
\hline Ratio of Depth/Width $\left(\mathrm{R}_{\mathrm{dw}}\right)$ & 1.47 & 2.24 & 1.68 & 2.85 & 1.00 & 1.86 & 1.82 & 0.47 & $1.00-2.85$ \\
\hline Total Room Surface (TS): $\left(\mathrm{m}^{2}\right)$ & 346.90 & 460.50 & 415.03 & 373.01 & 342.30 & 431.28 & 401.86 & 36.80 & $342.30-460.50$ \\
\hline \% of Absorbing Surface (PAS) & $17.71 \%$ & $11.73 \%$ & $30.00 \%$ & $4.25 \%$ & $1.75 \%$ & $8.13 \%$ & 12.64 & 7.69 & $1.75-30.00$ \\
\hline
\end{tabular}

Note. ENG=Faculty of Engineer, IDED=Faculty of Industrial Education, ARCH=Faculty of Architecture, $\mathrm{SCI}=$ Faculty of Science, AGRI=Faculty of Agriculture, IT=Faculty of Information Technology

Moreover, the table shows spatial component factors that will be analyzed to define their relationship with STI value in a room, which consist of (1) Room Volume (RV), (2) Ceiling Height (CH), (3) the Ratio of Depth to Width $\left(\mathrm{R}_{\mathrm{dw}}\right)$, (4) Total Room Surface (TS), and (5) Percentage of Absorbing Surface areas (PAS). For the volume of the six studied classrooms, the minimum was 318.66 cubic meters, maximum was 428.34 cubic meters, and the average value was 391.74 cubic meters. These room volumes fall under the ANSI S12.60 standard as a large classroom. In addition, measurements obtained gave an average ceiling height of 3.05 meters. The ratio of depth to width started from 1.00, for a room with a depth equal to a width, and more than 1.00 for a room that had a depth higher than the width dimension. Thus, if ratio value is high, it means that that the room is very deep. In this case, depth to width ratio ranges from 1.00 to 2.85 . Total room surface factor had values starting from 342.3 to 460.5 square meters, and the average value of the percentage of absorption surface factor stood at $12.64 \%$, the minimum was $1.75 \%$ and the maximum was $30 \%$.

\subsection{Acoustical Environment Analysis}

\subsubsection{Background Noise Level (BNL)}

The values summarization of Background Noise Level (BNL) in the classrooms, Figure 7 shows that none of the selected classrooms met the standard acoustic value. Only the ARCH classroom, at $45.25 \mathrm{dBA}$, was the closest to standard. When air-conditioning systems were turned on, each room had a much higher BNL (67.47 dBA) with 
an average increase of $32.2 \%$. In addition, it was observed that when the rooms contained acoustic absorbing materials, BNL value decreased but varied according to the Percentage of Absorbing Surfaces (PAS) in the room. ARCH classroom had an acoustic absorbing surface of $30 \%$ and was able to reduce BNL value by $3.94 \%$. For AGRI classroom, it had a very little acoustic absorbing surface that the cause of BNL value only dropped by $0.06 \%$. Nonetheless, the measured results were obtained from real classrooms which had many acoustical related factors such as room volume, ceiling height, and room proportion, which were considered and a relationship between occurring spatial factors and acoustical characteristics were investigated via support from statistical program analysis.

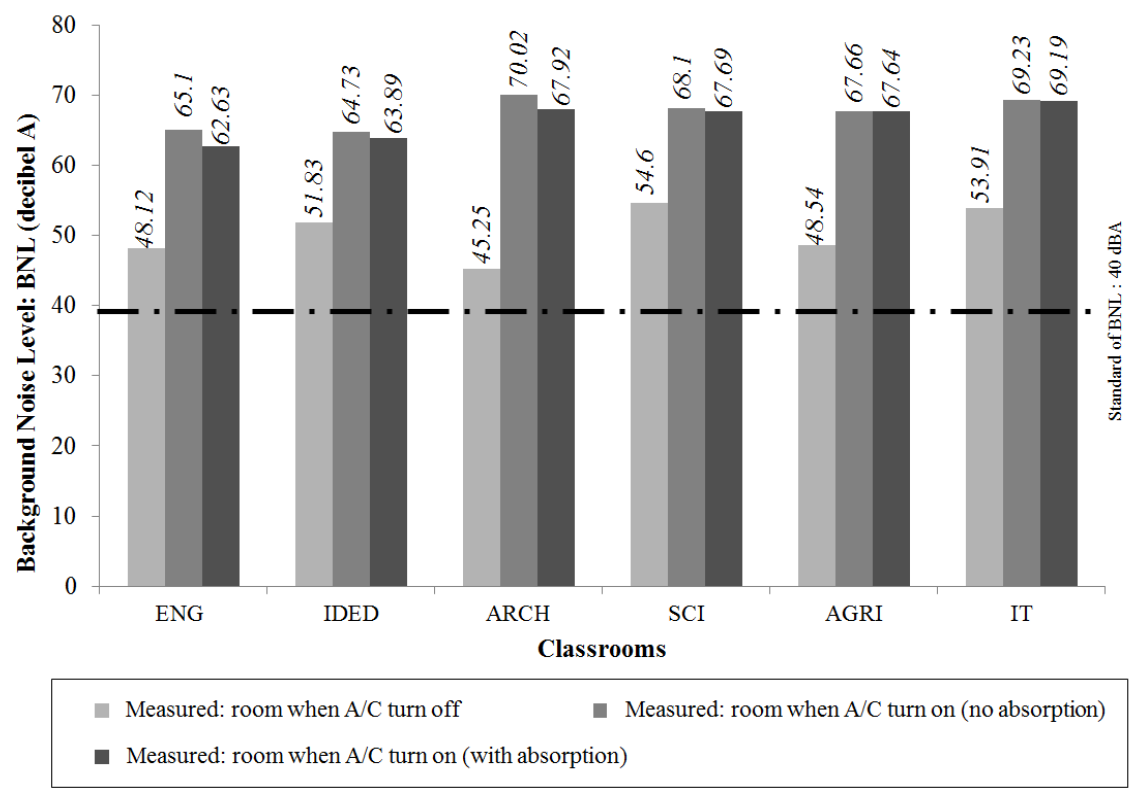

Figure 7. Comparison between Background Noise Levels

Note. $\mathrm{ENG}=$ Faculty of Engineer, IDED=Faculty of Industrial Education, ARCH=Faculty of Architecture, $\mathrm{SCI}=$ Faculty of Science, AGRI=Faculty of Agriculture, IT=Faculty of Information Technology

\subsubsection{Reverberation Time (RT)}

The measurement of RT value used the balloon bursting sound (impulse noise), created from the sound generator with loudness level set at BNL+60 dBA (BNL of each room). Frequency interval for RT measurement was $500-$ $2000 \mathrm{~Hz}$, which is a normal speaking frequency interval. Reverberation time for a room with volume higher than 288 cubic meters but lower than 566 cubic meters, according to ANSI S12.60 standard, should not exceed 0.7 seconds. The RT value summarization, shown in Figure 8, all six classrooms had RT values higher than that of the standard with an average of 1.73 seconds, the standard deviation of 0.49 , minimum value of 1.27 , and maximum value of 2.55 seconds.

However, when acoustic absorbing materials were added to the rooms, a new average value was reduced to 1.54 seconds (SD 0.57), the minimum value of 1.06, and the maximum value of 2.50 seconds. In other words, when rooms contain acoustic absorbing materials, it will cause reverberation time to drop by $11.77 \%$ on average depending on a number of acoustic absorbing surfaces or the percentage of absorbing surface areas in the rooms. For rooms with the high acoustic absorbing surface, there will be a more significant reduction in RT value than rooms with little acoustic absorption surface. 


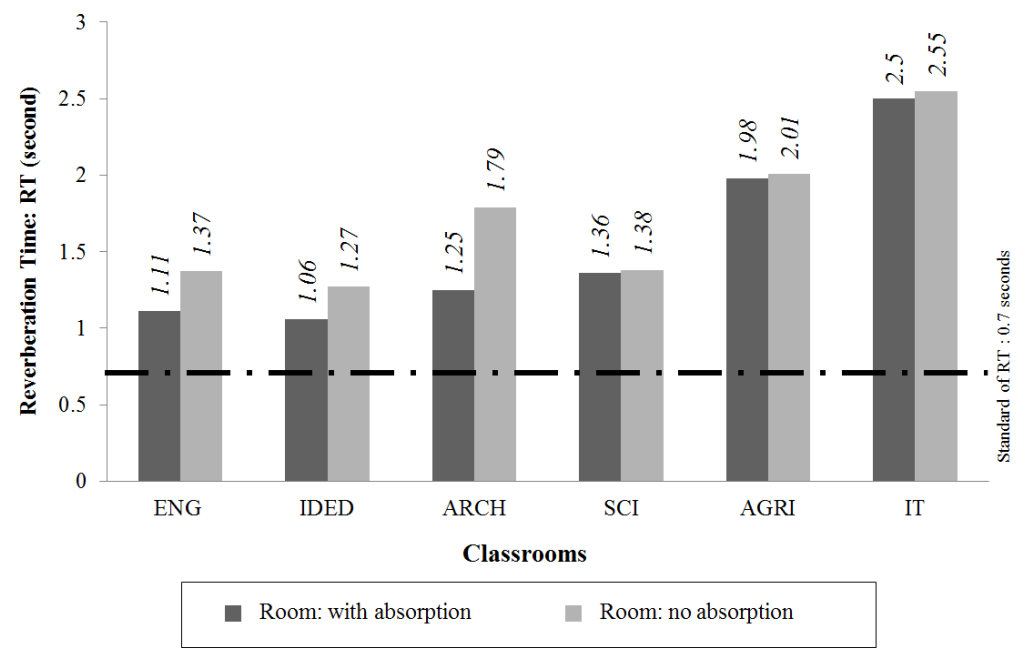

Figure 8. Comparison between Reverberation Times

Note. $\mathrm{ENG}=$ Faculty of Engineer, IDED=Faculty of Industrial Education, ARCH=Faculty of Architecture, $\mathrm{SCI}=$ Faculty of Science, AGRI=Faculty of Agriculture, IT=Faculty of Information Technology

\subsubsection{Speech Transmission Index (STI)}

Speech Transmission Index (STI) value is an index used to indicate speech intelligibility. It tells important acoustic characteristic for rooms or areas that are used for communication such as classrooms. A suitable STI value for classrooms should exceed 0.60 referring to rooms with good clarity. From the STI value comparison of the six classrooms using in-field acoustical measurement method, the results show that the average values of STI in each room does not meet the standard criteria $(0.60)$, where the lowest average value obtained was 0.30 , and the highest average value was 0.59 . The detail of STI values in each room were shown in Table 4.

Table 4. STI value data of the six large classrooms

\begin{tabular}{|c|c|c|c|c|c|c|c|c|c|}
\hline \multirow{3}{*}{ Large classrooms } & \multirow{3}{*}{$\begin{array}{l}\text { PAS } \\
(\%)\end{array}$} & \multicolumn{8}{|c|}{ STI values } \\
\hline & & \multicolumn{4}{|c|}{ Room: with absorption } & \multicolumn{4}{|c|}{ Room: no absorption } \\
\hline & & Min. & Max. & Mean & $S D$ & Min. & Max. & Mean & $S D$ \\
\hline ENG: Faculty of Engineer & 17.71 & 0.55 & 0.61 & 0.58 & 0.023 & 0.44 & 0.54 & 0.48 & 0.034 \\
\hline IDED: Faculty of Industrial Education & 11.73 & 0.48 & 0.61 & 0.52 & 0.043 & 0.43 & 0.58 & 0.49 & 0.049 \\
\hline ARCH: Faculty of Architecture & 30.00 & 0.54 & 0.66 & 0.59 & 0.040 & 0.44 & 0.54 & 0.48 & 0.034 \\
\hline SCI: Faculty of Science & 4.25 & 0.46 & 0.56 & 0.50 & 0.030 & 0.44 & 0.56 & 0.49 & 0.036 \\
\hline AGRI: Faculty of Agriculture & 1.75 & 0.22 & 0.44 & 0.32 & 0.084 & 0.22 & 0.40 & 0.30 & 0.065 \\
\hline IT: Faculty of Information Technology & 8.13 & 0.33 & 0.41 & 0.35 & 0.026 & 0.31 & 0.41 & 0.34 & 0.030 \\
\hline
\end{tabular}

Note. PAS=the Percentage of Absorbing Surface area.

Figure 9 shows STI value distribution in each room comparing the conditions with and without acoustic absorbing surfaces. STI values in each room comparing the conditions with and without acoustic absorbing surfaces. When there was no acoustic absorbing surface, STI value of every room was lower than the standard value (0.60) but had normal distribution characteristics, which means sounds were clear only in the middle-front position close to the speaker, and clarity dropped when farther. The highest clarity value obtained was 0.58 , and the lowest was 0.22 .

However, when acoustic absorbing surfaces were added, STI average value of every room improved. Especially in ENG, IDED, and ARCH classrooms which had acoustic absorbing surfaces of $17.71 \%, 11.73 \%$, and $30 \%$ 
respectively. It can be observed that the average of STI values increased until the average value became close to the standard value. For SCI, AGRI, and IT classrooms which had little acoustic absorbing surfaces, average STI value did not increase significantly. Nonetheless, STI value distribution spread out with a greater radius, meaning that areas that had low acoustic clarity became clearer.
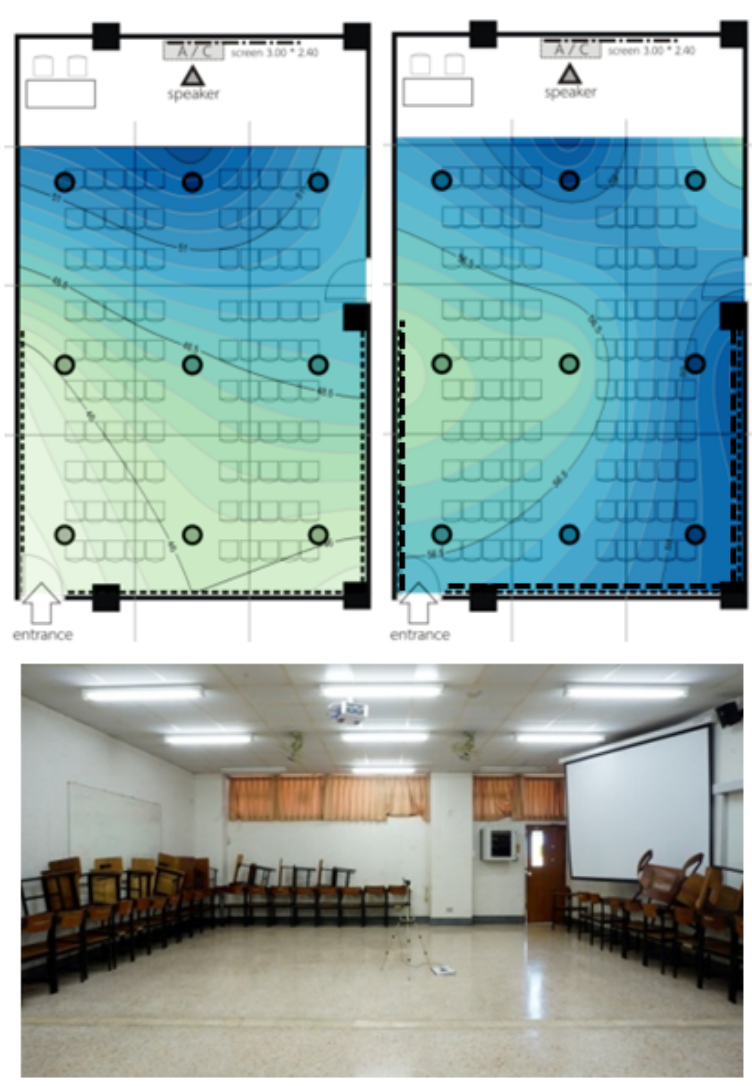

ENG: Faculty of Engineer [PAS=17.71\%] no absorption (left): Mean .48 [.44 - .54] with absorption (right): Mean .58 [.54 - .61]
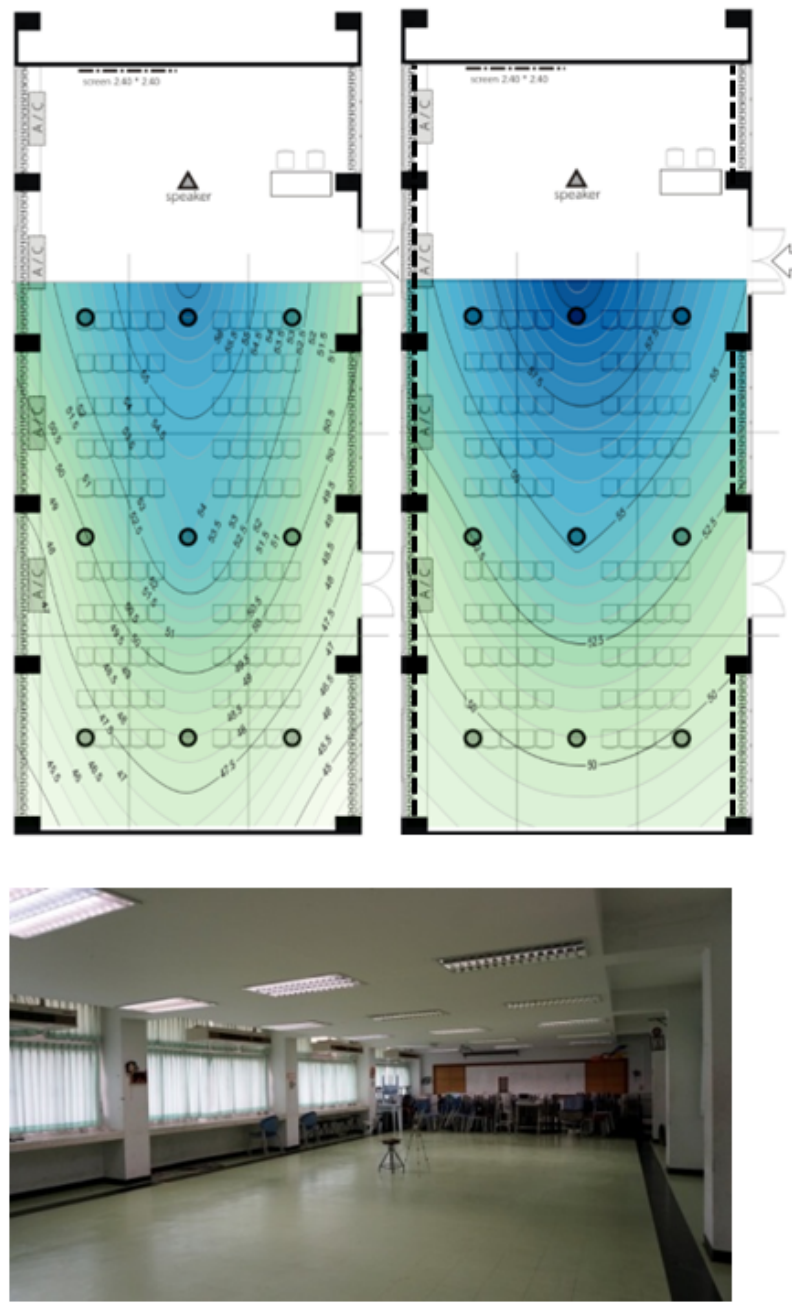

IDED: Faculty of Industrial Education [PAS=11.73\%] no absorption (left): Mean $.49[.43-.58]$ with absorption (right): Mean $.52[.48-.61]$

---- area of absorbing surface

Figure 9-1. STI contour maps shows STI value distribution of each room under conditions with and without acoustic absorbing surface areas

Note. The deep blue areas indicate regions with high STI value or high clarity, and light blue indicate low STI value or low clarity regions 

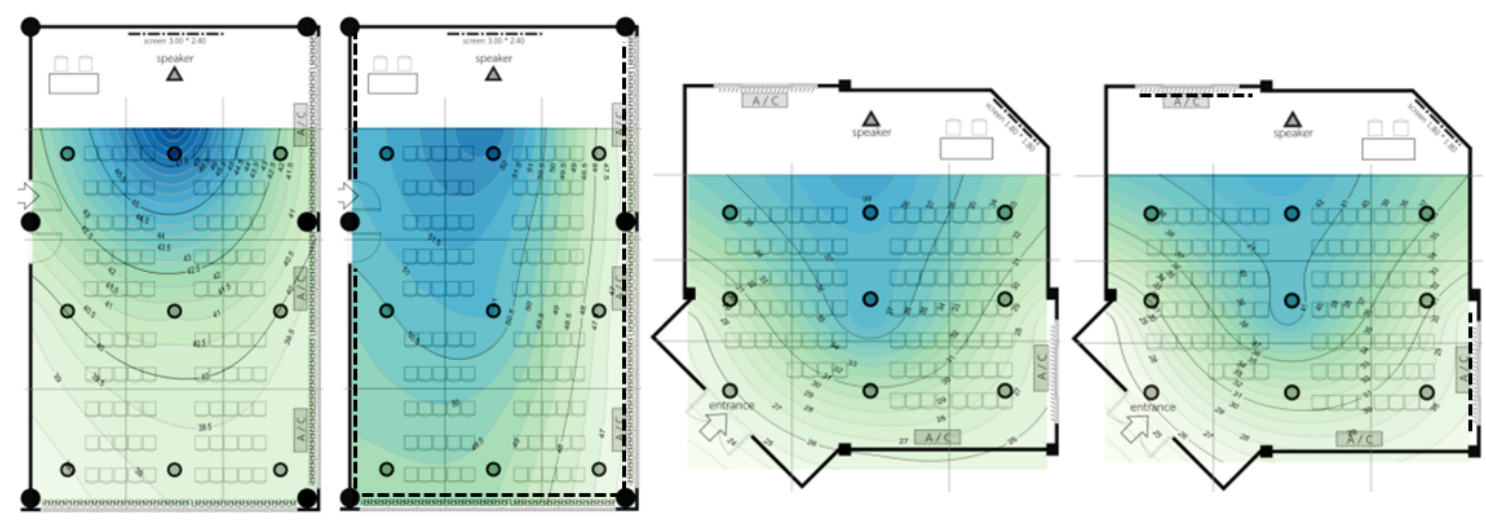

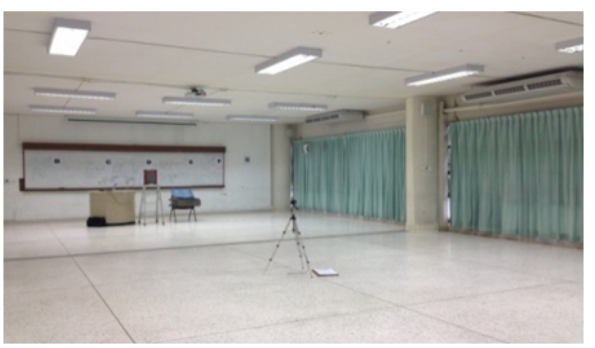

ARCH: Faculty of Architecture [PAS=30\%]

no absorption (left): Mean $.48[.44-.54]$

with absorption (right): Mean .59[.54- .66]
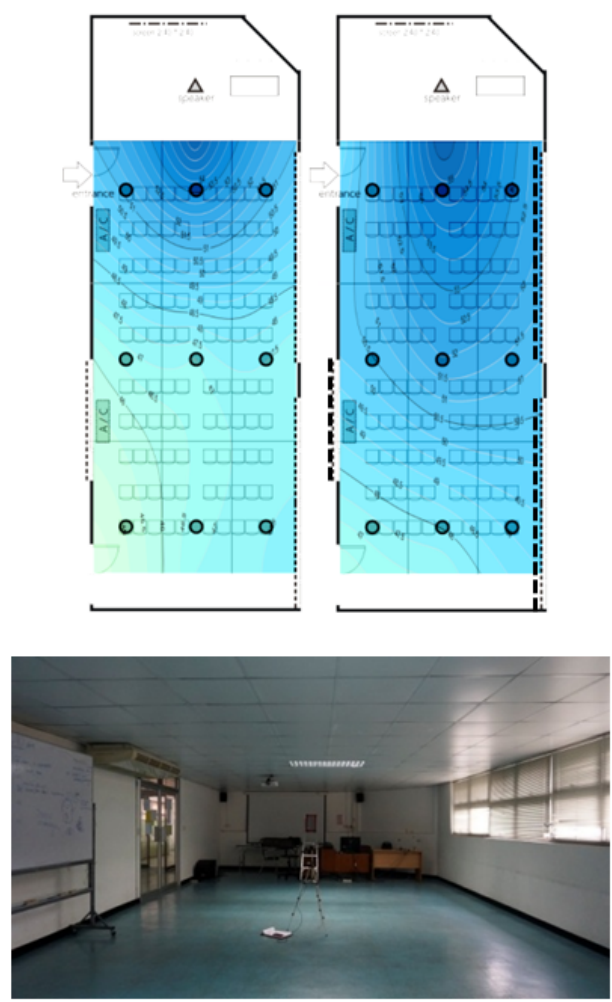

SCI: Faculty of Science $[\mathrm{PAS}=4.25 \%]$ no absorption (left): Mean $.49[.44-.56]$

with absorption (right): Mean $.50[.46-.56]$

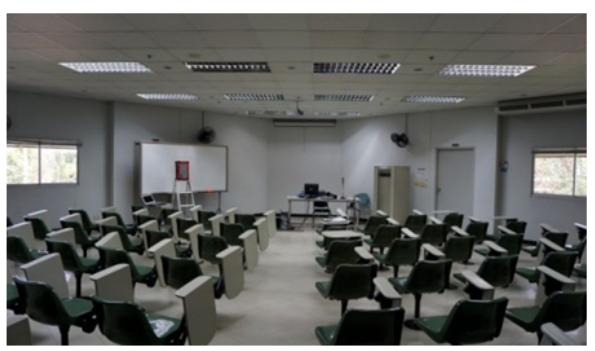

AGRI: Faculty of Agriculture [PAS=1.75\%]

no absorption (left): Mean $.30[.22-.40]$

with absorption (right): Mean $.32[.22-.44]$
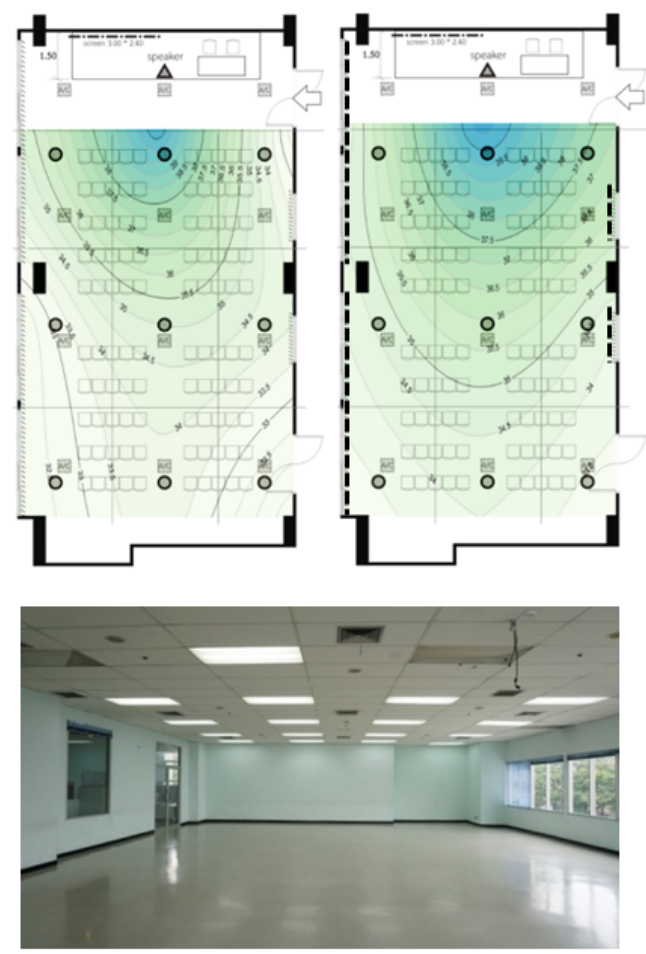

IT: Faculty of Information Technology [PAS=8.13\%] no absorption (left) Mean .34 [.31 - .41]

with absorption (right): Mean $.35[.33-.41]$

\section{---- area of absorbing surface}

Figure 9-2. STI contour maps shows STI value distribution of each room under conditions with and without acoustic absorbing surface areas 


\subsection{Regression Statistical Analysis: to develop the model of Thailand Speech Intelligibility (T-SI)}

The Thailand Speech Intelligibility (T-SI) model, the equation used to predict the STI value, was developed by the multiple regression analysis. The regression analysis at $95 \%$ confidence level was used via Stepwise method between STI variable and five dependent variables consisting of (1) Room Volume (RV), (2) Ceiling Height $(\mathrm{CH})$, (3) the Ratio of Depth to Width $\left(\mathrm{R}_{\mathrm{dw}}\right)$, (4) Total Room Surface (TS), and (5) Percentage of Absorbing Surface areas (PAS). Table 5 shows that PAS was the first factor that was able to predict STI value, followed by $\mathrm{R}_{\mathrm{dw}}, \mathrm{CH}, \mathrm{RV}$, and TS. When taking into account the results from Table 6, it can be seen that all five spatial component factors have a high influence on STI value with multiple correlation coefficients of 0.854 , and they were able to predict 72.9 percent of STI value with 0.05 significance and standard deviation of 0.051 .

Table 5. Multiple correlation coefficients (R) and coefficient of determination (R2) increment when each factor was gradually added

\begin{tabular}{|c|c|c|c|c|c|c|}
\hline Independent variables & $\mathrm{R}$ & $\mathrm{R}^{2}$ & $\mathrm{R}^{2}$ change & $\mathrm{SE}_{\text {est }}$ & $\mathrm{F}$ & p-value \\
\hline PAS & .605 & .366 & .364 & .078 & 237.562 & .000 \\
\hline PAS $R_{d w}$ & .687 & .472 & .470 & .071 & 183.800 & .000 \\
\hline PAS $\quad \mathrm{R}_{\mathrm{dw}} \quad \mathrm{CH}$ & .706 & .498 & .495 & .069 & 135.749 & .000 \\
\hline PAS $\quad R_{d w} \quad C H \quad R V$ & .723 & .523 & .518 & .068 & 111.985 & .000 \\
\hline $\begin{array}{lllll}\text { PAS } & \mathrm{R}_{\mathrm{dw}} & \mathrm{CH} & \mathrm{RV} & \mathrm{TS}\end{array}$ & .854 & .729 & .725 & .051 & 219.097 & .000 \\
\hline
\end{tabular}

Note. Dependent variable is STI value; Independent variables included PAS=Percentage of Absorbing surface areas, $\mathrm{R}_{\mathrm{dw}}=$ the Ratio of Depth to Width, $\mathrm{CH}=\mathrm{Ceiling}$ Height, $\mathrm{RV}=\mathrm{Room}$ volume, and $\mathrm{TS}=$ Total room surface

From the T-SI model and Table 6, an additional explanation can be deduced that $\mathrm{CH}$ factor was able to predict the highest STI value with the statistical significance of 0.05 while having regression coefficient $(b, \beta) 2.145$ and 6.364. This is followed by $\mathrm{R}_{\mathrm{dw}}$ factor $(\mathrm{b}=-.049, \beta=-.238)$ and TS factor $(\mathrm{b}=.026, \beta=9.682)$. PAS factor $(\mathrm{b}$ $=.002, \beta=.164)$ is the factor that predicts the lowest STI value. However, correlation analysis also shows that this T-SI model depended on the strongly positive relationship of PAS $(\mathrm{R}=.605)$. This means that the STI value is also influenced greatly by the PAS factor.

Table 6. Statistical analysis results via regression method to predict STI value that resulted from spatial component factors

\begin{tabular}{lccccc}
\hline Spatial component factors & $\mathrm{b}$ & $\mathrm{SE}_{\mathrm{b}}$ & $\beta$ & $\mathrm{t}$ & $\mathrm{p}$-value \\
\hline Room Volume $(\mathrm{RV})$ & -.023 & .001 & -10.965 & -17.894 & .000 \\
\hline Ceiling Height $(\mathrm{CH})$ & 2.145 & .116 & 6.364 & 18.435 & .000 \\
\hline Ratio of depth / width $\left(\mathrm{R}_{\mathrm{dw}}\right)$ & -.049 & .011 & -.238 & -4.529 & .000 \\
\hline Total Room Surface $(\mathrm{TS})$ & .026 & .001 & 9.682 & 17.595 & .000 \\
\hline Percentage of Absorbing Surface (PAS) & .002 & .001 & .164 & 4.011 & .000 \\
\hline
\end{tabular}

Constant $-7.322 ; \mathrm{SE}_{\mathrm{est}}=.051$

$$
\mathrm{R}=.854 ; \mathrm{R}^{2}=.729 ; \mathrm{F}=219.097 ; \mathrm{p} \text {-value }=.000
$$

Furthermore, when considering the regression coefficient, it was found that the five spatial component factors were able to predict STI value with the level of significance at 0.05 . Thus, the Thailand Speech Intelligibility model (T-SI model), STI value predicting equation that resulted from the five spatial component factors is as follows:

$$
S T I=-7.322-(023 * R V)+(2.145 * C H)-\left(049 * R_{d w}\right)+(.026 * T S)+(.002 * P A S)
$$

Note. Dependent variable is STI value; Independent variables included PAS=Percentage of Absorbing surface areas, $\mathrm{R}_{\mathrm{dw}}=$ the Ratio of Depth to Width, $\mathrm{CH}=$ Ceiling Height, $\mathrm{RV}=$ Room volume, and TS=Total room surface 
However, after getting T-SI model, main effect test of 5 spatial component factors was conducted by adjusting the value of each factor to observe changes of STI. Simulation in classrooms with 8.00 meters width, 12 meters depth, 3.15 meters height, and $30 \%$ absorbing surface meaning that 5 factors contain values of $\mathrm{RV}=300$, $\mathrm{CH}=3.15, \mathrm{Rd} / \mathrm{w}=1.5, \mathrm{TS}=315$, and $\mathrm{PAS}=30$. These values of the factors will be reduced $2.5 \%, 5 \%$, and $10 \%$ respectively. After the adjustment, changed of STI value can be observed in percent as shown in Table 7.

Table 7. T-SI model test

\begin{tabular}{|c|c|c|c|c|c|c|c|c|c|c|c|c|c|}
\hline Scenario & Constant & $\begin{array}{c}\mathrm{RV} \\
(\mathrm{b}=-.023)\end{array}$ & & $\begin{array}{c}\mathrm{CH} \\
(\mathrm{b}=2.145)\end{array}$ & & $\begin{array}{c}\mathrm{R}_{\mathrm{dw}} \\
(\mathrm{b}=-.049)\end{array}$ & & $\begin{array}{c}\text { TS } \\
(\mathrm{b}=.026)\end{array}$ & & $\begin{array}{c}\text { PAS } \\
(\mathrm{b}=.002)\end{array}$ & & STI & $\begin{array}{c}\text { STI } \\
\text { change } \\
(\%)\end{array}$ \\
\hline & -7.322 & 300 & -6.9 & 3.15 & 6.76 & 1.5 & -.074 & 315 & 8.19 & 30 & .06 & 0.711 & - \\
\hline $\mathrm{RV}[-2.5 \%]$ & & 292.5 & -6.73 & & & & & & & & & 0.884 & -24.25 \\
\hline $\operatorname{RV}[-5.0 \%]$ & & 285 & -6.56 & & & & & & & & & 1.056 & -48.51 \\
\hline RV [-10.0\%] & & 270 & -6.21 & & & & & & & & & 1.401 & -97.01 \\
\hline & -7.322 & 300 & -6.9 & 3.15 & 6.76 & 1.5 & -.074 & 315 & 8.19 & 30 & .06 & 0.711 & - \\
\hline $\mathrm{CH}[-2.5 \%]$ & & & & 3.07 & 6.58 & & & & & & & 0.542 & 28.82 \\
\hline $\mathrm{CH}[-5.0 \%]$ & & & & 2.99 & 6.41 & & & & & & & 0.368 & 48.25 \\
\hline $\mathrm{CH}[-10.0 \%]$ & & & & 2.84 & 6.08 & & & & & & & 0.036 & 94.99 \\
\hline & -7.322 & 300 & -6.9 & 3.15 & 6.76 & 1.5 & -.074 & 315 & 8.19 & 30 & .06 & 0.711 & - \\
\hline $\mathrm{R}_{\mathrm{dw}}[-2.5 \%]$ & & & & & & 1.46 & -.072 & & & & & 0.713 & -0.28 \\
\hline $\mathrm{R}_{\mathrm{dw}}[-5.0 \%]$ & & & & & & 1.43 & -.069 & & & & & 0.715 & -0.52 \\
\hline $\mathrm{R}_{\mathrm{dw}}[-10.0 \%]$ & & & & & & 1.35 & -.066 & & & & & 0.718 & -1.03 \\
\hline & -7.322 & 300 & -6.9 & 3.15 & 6.76 & 1.5 & -.074 & 315 & 8.19 & 30 & .06 & 0.711 & - \\
\hline TS $[-2.5 \%]$ & & & & & & & & 307.13 & 7.98 & & & 0.507 & 28.78 \\
\hline TS $[-5.0 \%]$ & & & & & & & & 299.25 & 7.78 & & & 0.302 & 57.57 \\
\hline TS [-10.0\%] & & & & & & & & 283.5 & 7.37 & & & -0.107 & 115.14 \\
\hline & -7.322 & 300 & -6.9 & 3.15 & 6.76 & 1.5 & -.074 & 315 & 8.19 & 30.0 & .060 & 0.711 & - \\
\hline PAS $[-2.5 \%]$ & & & & & & & & & & 27.5 & .055 & 0.706 & 0.70 \\
\hline PAS $[-5.0 \%]$ & & & & & & & & & & 25.0 & .050 & 0.701 & 1.41 \\
\hline PAS $[-10.0 \%]$ & & & & & & & & & & 20.0 & .040 & 0.691 & 2.81 \\
\hline
\end{tabular}

Note. Dependent variable is STI value; Independent variables included PAS=Percentage of Absorbing surface areas, $\mathrm{R}_{\mathrm{dw}}=$ the Ratio of Depth to Width, $\mathrm{CH}=$ Ceiling Height, $\mathrm{RV}=$ Room volume, and $\mathrm{TS}=$ Total room surface

Testing T-SI formula shows the change in STI from the effect of 5 spatial component factors. Information from Table 7 concludes that factors with most effect are STI are TS, RV, CH, PAS, and $\mathrm{R}_{\mathrm{d} / \mathrm{w}}$ respectively because factors Ts and RV contain relatively high values $(315,300)$. When the two factors slightly change, they affect the value of STI considerably. It can be noticed that the value of $\mathrm{CH}$ or ceiling height is not high (3.15) but it significantly affects STI while PAS slightly affects STI value.

According to T-SI formula, it shows that five spatial component factors affect STI, especially room volume and ceiling height factors. Thus, the importance of the two factors needs to be aware of buildings in the design process. For buildings that have been completely constructed and using, improving the internal sound environment by changing room volume will affect structure and system work of the building which means that budget for improvement will be unnecessarily high. Improving can be done by lifting up the height of ceiling or increasing absorbing surface in the room. If it is done properly, it can improve speech intelligibility as well.

\section{Conclusions}

This research studied spatial component factors that affect the acoustic environment within a building. The 
objectives of the research were (1) to evaluate the acoustical environments and (2) to forecast STI values from spatial component variables. The studied areas were six selected large classrooms all belonging to a Thai public institution. The five spatial component factors were collected, namely, RV, CH, $\mathrm{R}_{\mathrm{d} / \mathrm{w}}, \mathrm{TS}$, and PAS. The room acoustical environments were evaluated through the three acoustical indexes which were BNL, RT, and STI. The research results were separated into the following two sections.

Section 1: Acoustic environment evaluation. Background Noise Level (BNL) or ambient noise of all selected classrooms exceeded the standard value (40 dBA) having average values in the range of 42.25-54.60 dBA. The classroom that had the lowest BNL value was the room that contained the highest amount of acoustic absorbing material (PAS 30\%). The average of BNL values rose by $32.2 \%$ when air-conditioning systems of every room was turned on. Similarly, Reverberation Time (RT) of every room exceeded the standard value (0.7 seconds) with an average value of 1.27 seconds and a maximum value at 2.55 seconds. When acoustic absorbing surfaces were added, the average value reduced by $11.77 \%$. For Speech Transmission Index (STI) value, values obtained from all classrooms went below their standard value $(0.60)$. Under no acoustic absorbing surface condition, STI value stood at $0.30-0.49$. However, when acoustic absorbing surfaces were added, the value increased to $0.32-0.59$. Thus, apart from improving sound clarity, acoustic absorbing surfaces also help in spreading sound clarity across the room.

Section 2: T-SI model, STI value predicting equation based on spatial component factors. The five spatial component factors that affected STI value with statistical significance at $95 \%$ confidence level were RV, $\mathrm{CH}$, $\mathrm{R}_{\mathrm{d} / \mathrm{w}}$, TS, and PAS. Furthermore, the CH factor gave the highest STI value prediction, followed by $\mathrm{R}_{\mathrm{d} / \mathrm{w}}, \mathrm{TS}, \mathrm{RV}$, and PAS. However, PAS factor was the first factor that was able to predict STI value with the strong relationship.

The results of this research show that spatial component factors impacting the acoustical environment condition of the building occurred. There are many educational institutions in Thailand that presently suffer from acoustic issues. However, it is difficult and costly to improve existing classrooms by altering spatial component factors that affect building structure. If considering suitability, the building spatial component that can be modified is the amount of acoustic absorbing surface within rooms. In addition, modification amount or suitable placement for acoustic absorbing surfaces requires more in-depth research, where activities conducted within the room as well as human recognition are taken into account.

\section{Acknowledgments}

Researchers would like to highly acknowledge Bangkok University, our fund sponsor. We would also like to thank our thesis advisor and the acoustic specialist team that provided knowledge and understanding in data collection and analysis. Furthermore, we would like to acknowledge and send our regards to KMITL, which provided support for data collection and locations until completion.

\section{References}

ANSI-S12.60. (2002). American National Standard Institute-acoustical performance criteria, design requirements, and guidelines for schools. New York: Acoustical Society of America. Retrieved from $\mathrm{http} / / / \mathrm{www} . s o u n d i v i d e . c o m /$ uploads/content_file/asa_acoustic_requirements_for_schools-50.pdf

Astolfi, A., Corrado, V., \& Griginis, A. (2008). Comparison between measured and calculated parameters for the acoustical characterization of small classrooms. Applied Acoustics, 69, 966-976. http://doi.org/10.1016/j.apacoust.2007.08.001

Asutay, E., Vastfjall, D., Tajadura-Jimenez, A., Genell, A., Bergman, P., \& Kleiner, M. (2012). Emoacoustics: A study of the psychoacoustical and psychological dimensions of emotional sound design. Journal of the Audio Engineering Society, 60(1/2), 21-28. Retrieved from http://www.academia.edu/1650139

Barron, M. (2001). Late lateral energy fractions and the envelopment question in concert halls. Applied Acoustics, 62, 185-202. http://doi.org/10.1016/S0003-682X(00)00055-4

Bistafa, S., \& Bradley, J. (2000). Reverberation time and maximum background noise level for classrooms for a comparative study of speech intelligibility metrics. The Journal of the Acoustical Society of America, 107(2), 861-875. http://dx.doi.org/10.1121/1.428268

Bradley, J. (1986a). Predictors of speech intelligibility in rooms. The Journal of the Acoustical Society of America, 80(3). 837-845. http://dx.doi.org/10.1121/1.393907

Bradley, J. (1986b). Speech intelligibility studies in classrooms. The Journal of the Acoustical Society of America, 80(3). 846-854. http://dx.doi.org/10.1121/1.393908

Fuchs, H., Zha, X., Zhou, X., \& Drotleff, H. (2001). Creating low-noise environments in communication rooms. 
Applied Acoustics, 62, 1375-1396. http://doi.org/10.1016/S0003-682X(01)00008-1

Hodgson, M. (1999). Experimental investigation of the acoustical characteristics of university classrooms. The Journal of the Acoustical Society of America, 106, 1810. http://dx.doi.org/10.1121/1.427931

IEC 60268-16 (2011). Objective rating of speech intelligibility by speech transmission index (4th ed.). Geneva: International Electrotechnical Commission. Retrieved from https://webstore.iec.ch/publication/1214

Klatte, M., \& Hellbruck, J. (2010, June). Effects of classroom acoustics on performance and well-being in elementary school children: A field study. Paper presented at the thirty-ninth International Congress and Exposition on Noise Control Engineering, Internoise 2010, Lisbon, Portugal. Retrieved from http://www.spacustica.pt/internoise2010

Larm, P., Keranen, J., Helenius, R., Hakala, J., \& Hongisto, V. (2004, June). Acoustics in open-plan offices - A laboratory study. Paper presented at the Joint Baltic-Nordic Acoustics Meeting 2004 (pp. 2021-2025). Mariehamn, Aland. Retrieved from http://www.akustinenseura.fi/wp-content/uploads/2013/08/o15.pdf

Leeniva, P. \& Upala, P. (2015, June). Integration of psychoacoustics and activities in the learning environment. Proceedings of the European Network for Housing Research, ENHR 2015. Lisbon, Portugal. Abstract retrieved from http://www.enhr2015.com/images/residential_Buildingsd_v3.pdf

Leeniva, P. \& Upala, P. (2017, January). Evaluation of sound absorption performance of large lecture rooms in public university. Proceedings of the International Symposium on Social Sciences and Management, ISSSM 2017 (pp. 366-377). Sapporo. Hokkaido: Higher Education Forum.

Nijs, L., \& Rychtarikova, M. (2011). Calculating the optimum reverberation time and absorption coefficient for good speech intelligibility in classroom design U50. Acta Acustica united with Acustica, 97(1), 93-102. https://dx.doi.org/10.3813/AAA.918390

Paradis, R. (2014) Acoustic Comfort. Washington, DC: National Institute of Building Sciences, Whole Building Design Guide. Retrieved from https://www.wbdg.org/resources/acoustic-comfort

Peng, J. (2010). Chinese speech intelligibility at different speech sound pressure levels and signal-to-noise ratios in simulated classrooms. Applied Acoustics, 71 (4), 386-490. http://doi.org/10.1016/j.apacoust.2009.10.004

Rabelo, A., Santos, J., Oliveira, R., \& Magalhaes, M. (2014). Effect of classroom acoustics on the speech intelligibility of students. CoDAS, 26 (5). http://dx.doi.org/10. 1590/2317-1782/20142014026

Sala, E., \& Viljanen, V. (1995). Improvement of acoustics conditions for speech communication in classrooms. Applied Acoustics, 45, 81-91. https://doi.org/10.1016/0003-682X(94)00035-T

Tang, S. K., \& Wong, C. T. (1998). Performance of noise indices in office environment dominated by noise from human speech. Applied Acoustics, 55(4), 293-305. http://doi.org/10.1016/S0003-682X(98)00008-5

Tang, S. K., \& Yeung, M. H. (2003). Speech transmission index or rapid speech transmission index for classrooms? A designer's point of view. Journal of Sound and Vibration, 276, 431-439. https://doi.org/ 10.1016/j.jsv.2003.10.036

Zannin, P. H., \& Marcon, C. R. (2007). Objective and subjective evaluation of the acoustic comfort in classrooms. Applied Ergonomics, 38, 675-680. http://doi.org/10. 1016/j.apergo.2006. 10.001

\section{Copyrights}

Copyright for this article is retained by the author(s), with first publication rights granted to the journal.

This is an open-access article distributed under the terms and conditions of the Creative Commons Attribution license (http://creativecommons.org/licenses/by/4.0/). 